\title{
High-risk human papillomavirus infections in breast cancer in Syrian women and their association with Id-I expression: a tissue microarray study
}

\author{
N Akil ${ }^{1,4}$, A Yasmeen ${ }^{2,4}$, A Kassab ${ }^{2}$, L Ghabreau', AD Darnel ${ }^{2,3}$ and A-E Al Moustafa, ${ }^{* 1,2,3}$ \\ 'Faculty of Medicine, University of Aleppo, Aleppo, Syria; ${ }^{2}$ Segal Cancer Centre, Lady Davis Institute for Medical Research of the Sir Mortimer B. \\ Davis-Jewish General Hospital, McGill University, Montreal, Quebec, Canada; ${ }^{3}$ Program in Cancer Genetics, Department of Oncology, McGill University, \\ Montreal, Quebec, Canada
}

\begin{abstract}
High-risk human papillomaviruses (HPVs) could be important risk factors for breast carcinogenesis and metastasis. Based on this hypothesis, we recently studied the effect of E6/E7 onco-proteins of high-risk HPV type 16 in two non-invasive human breast cancer cell lines, BT20 and MCF7; we reported that E6/E7 converts these cell lines to invasive cells. This is accompanied by an overexpression of $\mathrm{Id}-\mathrm{I}$, which is an important regulator of breast metastasis. In this investigation, we examined the presence of highrisk HPVs (16, 18, 31, 33 and 35) and the expression of their E6 onco-protein as well as their correlation with Id-I gene expression, using polymerase chain reaction (PCR) and tissue microarray (TMA) analysis, respectively, in a cohort of I I 3 Syrian breast cancer patients. We found that high-risk HPV types 16, 18, 31, 33 and 35 are present in 8.84, 9.73, 7.07, 55.75 and 37.16\% of our samples, respectively, which represent invasive breast cancers. Overall, 69 (61.06\%) of the 113 samples are HPV positive; among these specimens 24 tissues (34.78\%) are coinfected with more than one HPV type. Furthermore, we report that the expression of the E6 onco-protein of these high-risk HPVs is correlated with Id-I overexpression in the majority of invasive breast cancer tissue samples. Our data suggest that high-risk HPV infections are associated with human breast cancer progression in Syrian women. British Journal of Cancer (2008) 99, 404-407. doi:I0.1038/sj.bjc.6604503 www.bjcancer.com
\end{abstract}

Published online 22 July 2008

(c) 2008 Cancer Research UK

Keywords: breast cancer; high-risk HPV; Id- I gene

High-risk human papillomaviruses (HPVs) are important risk factors for numerous human cancers including cervical, colorectal and head and neck (HN); as roughly 96,80 and $28 \%$ of these cancers are positive for high-risk HPVs, respectively (Damin et al, 2007; Sturgis and Cinciripini, 2007; de Sanjosé et al, 2007). In addition, the presence of high-risk HPVs serve as prognostic factors in early-stage cervical, colorectal and HN cancers, and are associated with vascular invasion, lymph node metastases and tumour size (Begum et al, 2003; Graflund et al, 2004; Zuna et al, 2004; Umudum et al, 2005; Varnai et al, 2006). The E6 and E7 onco-proteins of high-risk HPVs, which are constitutively expressed in these cancers, inactivate p53 and pRb tumour suppressors, respectively (Vousden, 1995). E6 facilitates the degradation of p53 through its association with an accessory protein, E6-AP, a component of the ubiquitin proteolytic pathway (Scheffner et al, 1993). Although, E7 proteins of high-risk HPVs bind to Rb (Dyson et al, 1989), as well as to other pocket proteins, such as p107 and p130 (Dyson et al, 1992), leading to cell cycle

*Correspondence: Professor A-E Al Moustafa, Segal Cancer Centre, Lady Davis Institute for Medical Research of the Sir Mortimer B DavisJewish General Hospital, 3755, Ch. de la Cote Ste-Catherine, Montréal, Québec, Canada H3T IE2.

E-mails: ala-eddin.almoustafa@mcgill.ca or aalmoust@Idi.jgh.mcgill.ca

${ }^{4}$ These authors contributed equally to this work.

Received 28 March 2007; revised 31 May 2008; accepted 10 June 2008; published online 22 July 2008 deregulation. This results in genomic instability and has been implicated in the progression of normal cells into cancer cells.

Several recent studies reported that approximately $50 \%$ of human breast cancers are positive for high-risk HPVs, especially types 16, 18 and 33 (Yu et al, 2000; Liu et al, 2001; de Villiers et al, 2005; Kan et al, 2005); controversially a few studies revealed that HPV could not be detected in breast cancer and normal tissues (Gopalkrishna et al, 1996; Lindel et al, 2007). On the other hand, studies that found HPV-positive samples revealed that certain types of high-risk HPV infections are linked to specific geographic locations. According to this observation, we recently reported that HPV type 16 is the only type of high-risk HPV present in breast cancer tissues of Canadian women (Yasmeen et al, 2007a).

The Id-1 gene (inhibitor of differentiation and DNA binding), a member of the helix-loop-helix transcription factor family, has multiple functions, including inhibition of differentiation, induction of proliferation and delaying replicative senescence (Fong et al, 2004; Sikder et al, 2003). Moreover, Id-1 has been suggested as a potential oncogene, because it is upregulated in many types of human cancer such as breast, prostate and cervical (Lin et al, 2000; Schindl et al, 2001; Ouyang et al, 2002). In breast cancer patients, enhanced Id-1 expression is correlated with more aggressive behaviour as well as much shorter overall survival (Schoppmann et al, 2003; Jang et al, 2006). These studies suggest that Id-1 plays a positive role in promoting the development and progression of human breast cancer. 
This study aims to recognise the specific types of high-risk HPV infections present in Syrian women and their association with tumour aggressiveness and Id-1 overexpression.

\section{MATERIALS AND METHODS}

\section{HPV detection and type specification}

A total of 113 blocks from breast cancer patients with a median age of 52 (range, 26-66) years were used in this study. Formalin-fixed (buffered neutral aqueous $10 \%$ solution), paraffin-embedded tumour materials were obtained from the Department of Pathology, Faculty of Medicine, University of Aleppo. The use of these specimens and data in research was approved by the Ethics Committee of the Faculty of Medicine of Aleppo University. Five $\mu \mathrm{g}$ of purified DNA (from each sample) was analysed for HPV by multiplex PCR targets to the conserved L1 region of the viral genome by use of PGMY09/11 L1 primer pools (Begum et al, 2003; Yasmeen et al, 2007a, b). In parallel, we used specific primers for E6 and E7 genes to detect HPV types 16, 18, 31, 33 and 35, whereas, specific primers for the GAPDH gene were used as an internal control (Table 1). PCR products were denatured in $0.13 \mathrm{~N} \mathrm{NaOH}$ and hybridised to an immobilised HPV probe array using an extended reverse line-blot assay for HPV genotyping (Roche Molecular Systems Inc., Alameda, CA, USA) of five HPV types classified as high-risk HPVs (types 16, 18, 31, 33 and 35) as described by Begum et al (2003).

\section{Tissue microarray}

The tissue microarray (TMA) construction was performed as described by Kuefer et al (2004). Briefly, tissue cylinders with a diameter of $0.6 \mathrm{~mm}$ were punched from representative tumour areas of a 'donor' tissue block using a semiautomatic robotic precision instrument. Two sections of the TMA blocks were transferred to an adhesive coated slide system (Instrumedics Inc.,

Table I The specific primer sets for E6 and/or E7 genes of high-risk HPVs used for PCR amplification

\begin{tabular}{|c|c|c|}
\hline HPV types & Region & Primers \\
\hline 16 & E6 & $\begin{array}{l}\text { 5'-ATGCACCAAAAGAGAACTGCA-3' } \\
\text { 5'-TTACAGCTGGGTTTCTCTACG-3' }\end{array}$ \\
\hline 16 & E7 & $\begin{array}{l}\text { 5'-ATGCATGGAGATACACCTACATTGCAT-3' } \\
\text { 5'-GTTTCTGAGAACAGATGGGGCACAC-3' }\end{array}$ \\
\hline 18 & E6 & $\begin{array}{l}\text { 5'-GCTITGAGGATCCAACACGG-3' } \\
\text { 5'-TGCAGCACGAATGGCACTGG-3' }\end{array}$ \\
\hline 31 & E7 & $\begin{array}{l}\text { 5'-GGGCTCATTTGGAATCGTGTG-3' } \\
\text { 5'-AACCATTGCATCCCGTCCCC-3' }\end{array}$ \\
\hline 33 & E6 & $\begin{array}{l}\text { 5'-TGTAACCGAAAGCGGTTCAA-3' } \\
\text { 5'-TAACGTTGGCTTGTGTCCTCTC-3' }\end{array}$ \\
\hline 33 & E7 & $\begin{array}{l}\text { 5'-TGAGGATGAAGGCTTGGACC-3' } \\
\text { 5'-TGACACATAAACGAACTGTG-3' }\end{array}$ \\
\hline 35 & E6 & $\begin{array}{l}\text { 5'-GGTCGTACCGAAAACGGTTG-3' } \\
\text { 5'- GTTGCCTCGGGTTCCAAATC-3' }\end{array}$ \\
\hline 35 & E7 & $\begin{array}{l}\text { 5'-CTATTGACGGTCCAGCT-3' } \\
\text { 5'-TACACACAGACGTAGTGTCG-3' }\end{array}$ \\
\hline
\end{tabular}

Primers specific for the GAPDH gene, 5'-GAAGGC-CATGCCAGTGAGCT-3' and 5'-CCGGGAAACTGTGGCGTGAT-3', were used as an internal control.
Hackensack, NJ, USA). Slides of the finished blocks were used for immunohistochemistry analysis.

\section{Immunohistochemistry}

Immunohistochemical procedures examining the expression of Id-1 and E6 were carried out using standard procedures as previously described (Al Moustafa et al, 2004). Primary specific antibodies were obtained from Santa Cruz Biotechnology and Calbiochem. Briefly, TMA sections were deparaffinised, rehydrated and endogenous peroxidase activity within the rehydrated tissue was blocked with a solution of $3 \%$ hydrogen peroxide in methanol for $10 \mathrm{~min}$ at room temperature. Antigen retrieval was carried out by boiling in $10 \mathrm{~mm}$ sodium citrate solution ( $\mathrm{pH} 6.0$ ) for $10 \mathrm{~min}$. The TMA slides were cooled and equilibrated in Optimax ${ }^{\mathrm{TM}}$ wash buffer then incubated overnight $(15 \mathrm{~h})$ at $4^{\circ} \mathrm{C}$ with primary antibodies for Id-1 (rabbit polyclonal; sc-488; Santa Cruz Biotechnology, Santa Cruz, CA, USA) and E6 (mouse monoclonal; clone C1P5; Calbiochem, San Diego, CA, USA). In all cases, the diluent was $0.6 \%$ BSA in Optimax wash buffer. Sections were then washed $(4 \times 1 \mathrm{~min})$, and the appropriate secondary HRP-conjugated antibody was applied for $1 \mathrm{~h}$ at room temperature (Calbiochem, Canada). The slides were counterstained with haematoxylin and mounted.

\section{RESULTS}

To determine the role of high-risk HPV infections in human breast cancer in Middle Eastern women, we investigated the presence of high-risk HPV types 16, 18, 31, 33 and 35 in a cohort of 113 breast cancer samples from Syrian women by PCR analysis using specific primers for their E6 and/or E7 genes (Table 1). Our study revealed that $69(61.06 \%)$ of the 113 samples are HPV positive and 24 $(34.78 \%)$ of these specimens are coinfected with more than one HPV type (Table 2). We found that HPV types 16,18 and 31 are present in only 10, 11 and 8 cancer tissues, respectively (Table 3 ). In contrast, 63 and 42 cancer tissues were positive for HPV types 33 and 35 , respectively (Table 3 ).

To assess the association between the presence of HPV types 16, 18, 31, 33 and 35 with tumour aggressiveness and Id-1 expression in breast cancer in Syrian women, we examined the expression of the E6 onco-protein of high-risk HPVs along with Id-1 expression

Table 2 High-risk $\operatorname{HPV}(16,18,31,33$ and 35) detection in breast carcinomas by PCR

\begin{tabular}{lccc}
\hline & Tested cases & Positive & Percentage \\
\hline Breast cancer tissues & 113 & 69 & 61.06 \\
\hline
\end{tabular}

The incidences of these viruses were found in 69 samples out of 113 examined using specific primers for E6 and/or E7 of each HPV type $(P<0.01)$. We noted that 24 samples of the 69 are infected with more than one HPV type $(P<0.01)$.

Table 3 Presence of HPV types 16, 18, 31, 33 and 35 in invasive and in-situ breast carcinomas

\begin{tabular}{lcccccc}
\hline & \multicolumn{5}{c}{ HPV types } \\
\cline { 3 - 7 } Breast cancer & No of cases & $\mathbf{1 6}$ & $\mathbf{1 8}$ & $\mathbf{3 1}$ & $\mathbf{3 3}$ & $\mathbf{3 5}$ \\
\hline Invasive & 87 & $9 / 87$ & $11 / 87$ & $8 / 87$ & $58 / 87$ & $39 / 87$ \\
In situ & 26 & $1 / 26$ & $0 / 26$ & $0 / 26$ & $5 / 26$ & $3 / 26$ \\
\hline
\end{tabular}

The presence of high-risk HPVs is more frequent in invasive breast cancer in comparison to in situ breast cancer tissues $(P<0.0001$ and 0.024$)$. Furthermore, it is clear that HPV type 33 and 35 are more common in breast cancer in Syrian women. 
406

in all our breast tissue samples by immunohistochemistry using tissue microarray methodology. We found that E6 expression is correlated with Id-1 overexpression in $94.25 \%$ of invasive breast cancer samples as opposed to $30.76 \%$ of in situ cancer tissues (Table 4 and Figure 1); whereas we presume that these in situ breast carcinomas, which are HPV-positive, will ultimately progress into invasive carcinomas under the effect of these HPVs, as they are already intermediate to high nuclear grade. Moreover, to confirm the association between E6/E7 of HPV types 16, 18, 31, 33 and 35 and Id-1, we investigated the presence of E6 and/or E7 of these viruses by PCR using specific primers for E6/E7 genes (Table 1). By means of this analysis, we were able to prove that E6/ E7 of HPV types 16, 18, 31, 33 and 35 are present in the majority of invasive breast cancer tissues; and their presence is associated with Id-1 overexpression (Table 4).

\section{DISCUSSION}

This is, to the best of our knowledge, the first study on the presence of high-risk HPVs and their relation with tumour aggressiveness in breast cancer in Syrian women. Earlier studies on breast cancer have reported that HPV types 11, 16 and 18 are the most frequent in women living in the United States and Brazil (Liu et al, 2001; Damin et al, 2004); and HPV type 18 is present in the majority of Australian women (Kan et al, 2005). In parallel, HPV type 33 is the most frequent virus in Asian women ( $\mathrm{Yu}$ et al, 1999, 2000). HPV type 16 has been identified in Italian and Norwegian women who had previous cervical neoplasias (Hennig et al, 1999). Moreover, we recently reported that HPV type 16 is the only type present in Canadian women. However, studies on the presence of high-risk HPV in the Middle East reveal that HPV types 18, 33 and 35 are present in breast cancer and normal mammary tissues in Turkish women (Gumus et al, 2006). On the other hand, the presence of HPVs in human breast cancer tissues

Table 4 Correlation between the expression of the E6 onco-protein of high-risk HPVs and Id-I in breast cancer tissues using tissue microarray analysis

\begin{tabular}{lccc}
\hline Breast cancer & No of cases & E6 of HPV & Id-I \\
\hline Invasive & 87 & $82 / 87$ & $84 / 87$ \\
In situ & 26 & $11 / 26$ & $8 / 26$ \\
\hline
\end{tabular}

The expression of the E6 onco-protein is associated with Id-I overexpression in the majority of invasive breast cancer tissues $(P<0.000 \mathrm{I})$. In contrast, this coexpression is limited to 8 cases out of 26 in in situ breast cancer $(P<0.0001)$. Furthermore, the expression levels of Id-I in these tissues vary from weak to moderate. varies from 12.9 to $86 \%$ (de Villiers et al, 2005; Tsai et al, 2005). In this study, we report that HPVs are present in $61.06 \%$ of breast cancer in Syrian women; moreover, HPV types 33 and 35 are the predominant viruses of the high-risk HPV family in these breast cancer tissues. Therefore, our data confirm that specific types of high-risk HPV infection, in breast tissues, are related to specific geographic locations.

Regarding the association between high-risk HPV and tumour aggressiveness, recent studies, including ours, have reported that the presence of HPV type 16, in human breast cancer, is correlated with invasive carcinomas (Kroupis et al, 2006; Yasmeen et al, 2007a). Moreover, we demonstrated that E6/E7 onco-proteins of HPV type 16 convert non-invasive breast cancer cells to an invasive phenotype (Yasmeen et al, 2007a); this is accompanied by an overexpression of Id-1, which regulates cell invasion and metastasis of human breast cancer cells (Desprez et al, 1998; Fong et al, 2003). In this study, we investigated the relation between high-risk HPVs and Id-1 expression in breast cancer tissues from Syrian women. We report, for the first time, that the presence of E6/E7 onco-proteins of HPV types 16, 18, 31, 33 and 35 are associated with Id-1 overexpression. Recently, Minn et al (2005) identified a subset of genes that mediate lung metastasis of human breast cancer; Id-1 was revealed as one of these important genes. We recently found that human breast cancer cells expressing E6/E7 of HPV type 16 display a major lung metastatic activity when compared with their wild type cells in vivo. Separately, we reported that the presence of E6/E7 of HPV type 16 is correlated with Id-1 overexpression in human invasive and metastatic breast cancer tissues in Canadian women. Moreover, we revealed that E6/E7 of HPV type 16 affects Id-1 deregulation through the activation of its promoter (Yasmeen et al, 2007a). Therefore, the present study clearly suggests that Id-1 is the downstream target of E6/E7 of HPV types 18, 31, 33 and 35 in human breast cancer progression.

In conclusion, we demonstrate that high-risk HPV types 16, 18, 31,33 and 35 are present in human breast cancer in Syrian women. In addition, HPV types 33 and 35 are the most dominant types of HPV infection found in Middle Eastern women, based on the combination of this study and a study by Gumus et al (2006). In parallel, we report that Id-1 is an important target for E6/E7 oncoproteins of HPV type 16, 18, 31, 33 and 35 in breast cancer cells. Our findings provide a new basis for understanding the mechanisms of high-risk HPV infections and their relation to human breast cancers. However, we firmly believe that further studies are required to elucidate the role and pathogenesis of high-risk HPV in human breast cancer, especially because HPV vaccines for only two high-risk HPV types are available at present. Therefore, it is of great interest to gain a better understanding of the association between HPV infections and breast cancer progression.
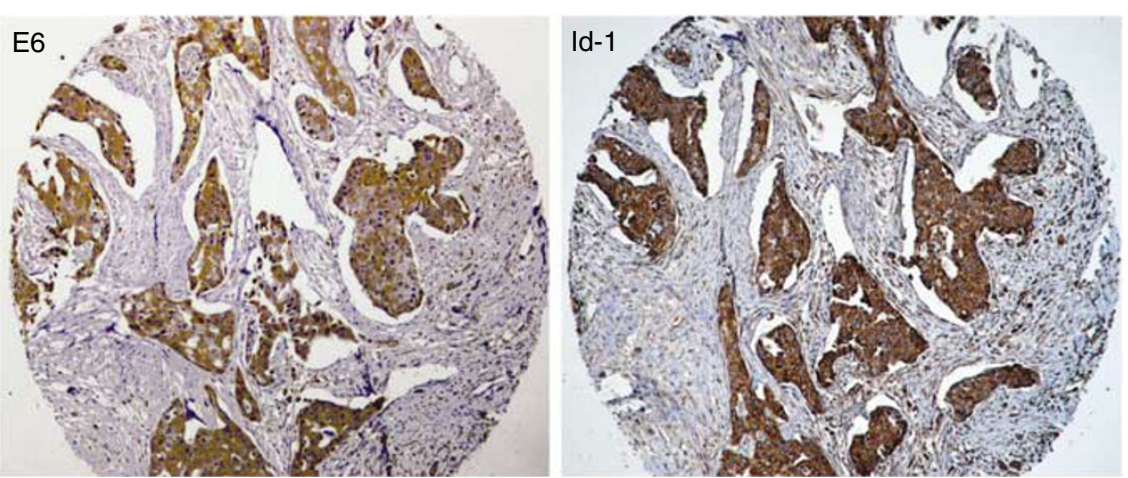

Figure I Association between the presence of HPV type 33 and Id- I overexpression in human invasive breast cancer in a sample patient. We noted that E6 expression of HPV type 33 is correlated with Id-I overexpression in invasive breast cancer using tissue microarray analysis. Magnification is $\times 200$. The presence of HPV type 33 was confirmed by PCR using specific primers for the E6 gene of this virus. 


\section{ACKNOWLEDGEMENTS}

We are grateful to Drs G Batist and W Foulkes for their support of this work. We are thankful to Dr TA Bismar and Ms M Crosato for their critical discussion and reading of the paper. We also thank Dr R Shammaa and R Ricciardi for their technical assistance. This work is supported by the Canadian Institutes for Health Research and the Fonds de la Recherche en Santé du Québec (FRSQ- Réseau du Cancer).

\section{REFERENCES}

Al Moustafa AE, Foulkes WD, Benlimame N, Wong A, Yen L, Bergeron J, Batist G, Alpert L, Alaoui-Jamali MA (2004) E6/E7 proteins of HPV type 16 and ErbB-2 cooperate to induce neoplastic transformation of primary normal oral epithelial cells. Oncogene 23: $350-358$

Begum S, Gillison ML, Ansari-Lari MA, Shah K, Westra WH (2003) Detection of human papillomavirus in cervical lymph nodes: a highly effective strategy for localizing site of tumor origin. Clin Cancer Res 9: $6469-6475$

Damin AP, Karam R, Zettler CG, Caleffi M, Alexandre CO (2004) Evidence for an association of human papillomavirus and breast carcinomas. Breast Cancer Res Treat 84: 131-137

Damin DC, Caetano MB, Rosito MA, Schwartsmann G, Damin AS, Frazzon AP, Ruppenthal RD, Alexandre CO (2007) Evidence for an association of human papillomavirus infection and colorectal cancer. Eur J Surg Oncol 33: $569-574$

de Sanjosé S, Diaz M, Castellsagué X, Clifford G, Bruni L, Muñoz N, Bosch FX (2007) Worldwide prevalence and genotype distribution of cervical human papillomavirus DNA in women with normal cytology: a metaanalysis. Lancet Infect Dis 7: 453-459

de Villiers EM, Sandstrom RE, zur Hausen H, Buck CE (2005) Presence of papillomavirus sequences in condylomatous lesions of the mamillae and in invasive carcinoma of the breast. Breast Cancer Res 1: R1-R11

Desprez PY, Lin CQ, Thomasset N, Sympson CJ, Bissell MJ, Campisi J (1998) A novel pathway for mammary epithelial cell invasion induced by the helix-loop-helix protein Id-1. Mol Cell Biol 18: 4577-4588

Dyson N, Guida P, Munger K, Harlow E (1992) Homologous sequences in adenovirus E1A and human papillomavirus E7 proteins mediate interaction with the same set of cellular proteins. J Virol 66: $6893-6902$

Dyson N, Howley PM, Munger K, Harlow E (1989) The human papilloma virus-16 E7 oncoprotein is able to bind to the retinoblastoma gene product. Science 243: $934-937$

Fong S, Debs RJ, Desprez PY (2004) Id genes proteins as promising targets in cancer therapy. Trends Mol Med 10: 387-392

Fong S, Itahana Y, Sumida T, Singh J, Coppe JP, Liu Y, Richards PC, Bennington JL, Lee NM, Debs RJ, Desprez PY (2003) Id-1 as a molecular target in therapy for breast cancer cell invasion and metastasis. Proc Natl Acad Sci USA 100: 13543-13548

Gopalkrishna V, Singh UR, Sodhani P, Sharma JK, Hedau ST, Mandal AK, Das BC (1996) Absence of human papillomavirus DNA in breast cancer as revealed by polymerase chain reaction. Breast Cancer Res Treat 39: 197-202

Graflund M, Sorbe B, Sigurdardottir S, Karlsson M (2004) HPV-DNA, vascular space invasion, and their impact on the clinical outcome in early-stage cervical carcinomas. Int J Gynecol Cancer 14: 896-902

Gumus M, Yumuk PF, Salepci T, Aliustaoglu M, Dane F, Ekenel M, Basaran G, Kaya H, Barisik N, Turhal NS (2006) HPV DNA frequency and subset analysis in human breast cancer patients' normal and tumoral tissue samples. J Exp Clin Cancer Res 25: 515-521

Hennig EM, Suo Z, Thoresen S, Holm R, Kvinnsland S, Nesland JM (1999) Human papillomavirus 16 in breast cancer of women treated for highgrade cervical intraepithelial neoplasia (CIN III). Breast Cancer Res Treat 53: $121-135$

Jang KS, Han HX, Paik SS, Brown PH, Kong G (2006) Id-1 overexpression in invasive ductal carcinoma cells is significantly associated with intratumoral microvessel density in ER-negative/node-positive breast cancer. Cancer Lett 244: 203-210

Kan CY, Iacopetta BJ, Lawson JS, Whitaker NJ (2005) Identification of human papillomavirus DNA gene sequences in human breast cancer. $\mathrm{Br} \mathrm{J}$ Cancer 93: $946-948$

Kroupis C, Markou A, Vourlidis N, Dionyssiou-Asteriou A, Lianidou ES (2006) Presence of high-risk human papillomavirus sequences in breast cancer tissues and association with histopathological characteristics. Clin Biochem 39: $727-731$

Kuefer R, Hofer MD, Gschwend JE, Rubin MA (2004) Tissue microarrays. High-throughput procedures to verify potential biomarkers. Urologe A 43: $659-667$

Lin CQ, Singh J, Murata K, Itahana Y, Parrinello S, Liang SH, Gillett CE, Campisi J, Desprez PY (2000) A role for Id-1 in the aggressive phenotype and steroid hormone response of human breast cancer cells. Cancer Res 60: $1332-1340$

Lindel K, Forster A, Altermatt HJ, Greiner R, Gruber G (2007) Breast cancer and human papillomavirus (HPV) infection: no evidence of a viral etiology in a group of Swiss women. Breast 16: $172-177$

Liu Y, Klimberg VS, Andrews NR, Hicks CR, Peng H, Chiriva-Internati M, Henry-Tillman R, Hermonat PL (2001) Human papillomavirus DNA is present in a subset of unselected breast cancers. J Hum Virol 4: 329-334 Minn AJ, Gupta GP, Siegel PM, Bos PD, Shu W, Giri DD, Viale A, Olshen AB, Gerald WL, Massague J (2005) Genes that mediate breast cancer metastasis to lung. Nature 436: $518-524$

Ouyang XS, Wang X, Lee DT, Tsao SW, Wong YC (2002) Over expression of ID-1 in prostate cancer. J Urol 167: 2598-2602

Scheffner M, Huibregtse JM, Vierstra RD, Howley PM (1993) The HPV-16 E6 and E6-AP complex functions as a ubiquitin-protein ligase in the ubiquitination of p53. Cell 75: 495-505

Schindl M, Oberhuber G, Obermair A, Schoppmann SF, Karner B, Birner P (2001) Overexpression of Id-1 protein is a marker for unfavorable prognosis in early-stage cervical cancer. Cancer Res 61: 5703-5706

Schoppmann SF, Schindl M, Bayer G, Aumayr K, Dienes J, Horvat R, Rudas M, Gnant M, Jakesz R, Birner P (2003) Overexpression of Id-1 is associated with poor clinical outcome in node negative breast cancer. Int J Cancer 104: 677-682

Sikder HA, Devlin MK, Dunlap S, Ryu B, Alani RM (2003) Id proteins in cell growth and tumorigenesis. Cancer Cell 3: 525-530

Sturgis EM, Cinciripini PM (2007) Trends in head and neck cancer incidence in relation to smoking prevalence: an emerging epidemic of human papillomavirus-associated cancers? Cancer 110: 1429-1435

Tsai JH, Tsai CH, Cheng MH, Lin SJ, Xu FL, Yang CC (2005) Association of viral factors with non-familial breast cancer in Taiwan by comparison with non-cancerous, fibroadenoma, and thyroid tumor tissues. J Med Virol 75: 276-281

Umudum H, Rezanko T, Dag F, Dogruluk T (2005) Human papillomavirus genome detection by in situ hybridization in fine-needle aspirates of metastatic lesions from head and neck squamous cell carcinomas. Cancer 105: $71-77$

Varnai AD, Bollmann M, Griefingholt H, Speich N, Schmitt C, Bollmann R, Decker D (2006) HPV in anal squamous cell carcinoma and anal intraepithelial neoplasia (AIN). Impact of HPV analysis of anal lesions on diagnosis and prognosis. Int J Colorectal Dis 21: 135-142

Vousden KH (1995) Regulation of the cell cycle by viral oncoproteins. Semin Cancer Biol 6: 109-116

Yasmeen A, Bismar TA, Kandouz M, Foulkes WD, Desprez PY, Al Moustafa AE (2007a) E6/E7 of HPV type 16 promotes cell invasion and metastasis of human breast cancer cells. Cell Cycle 6: 2038-2042

Yasmeen A, Ricciardi R, Kassab A, Bismar TA, Al Moustafa AE (2007b) High-risk HPVs in human breast cancer and normal mammary tissues. Breast 16: 445

Yu Y, Morimoto T, Sasa M, Okazaki K, Harada Y, Fujiwara T, Irie Y, Takahashi E, Tanigami A, Izumi K (2000) Human papillomavirus type 33 DNA in breast cancer in Chinese. Breast Cancer 7: 33-36

Yu Y, Morimoto T, Sasa M, Okazaki K, Harada Y, Fujiwara T, Irie Y, Takahashi E, Tanigami A, Izumi K (1999) HPV33 DNA in premalignant and malignant breast lesions in Chinese and Japanese populations. Anticancer Res 19: 5057-5061

Zuna RE, Allen RA, Moore WE, Mattu R, Dunn ST (2004) Comparison of human papillomavirus genotypes in high-grade squamous intraepithelial lesions and invasive cervical carcinoma: evidence for differences in biologic potential of precursor lesions. Mod Pathol 17: 1314-1322 